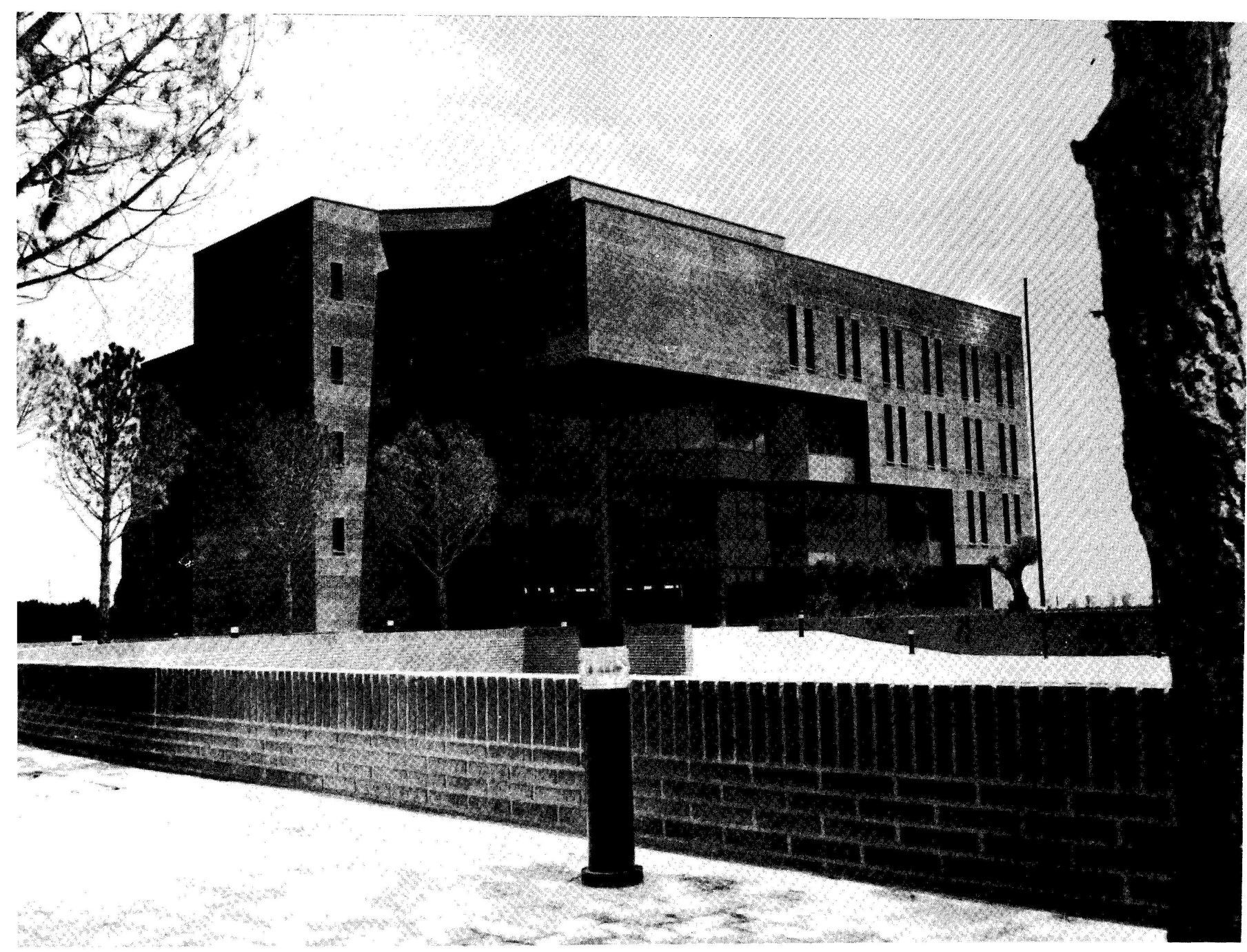

\title{
Edificio 3M, en Madrid - España
}

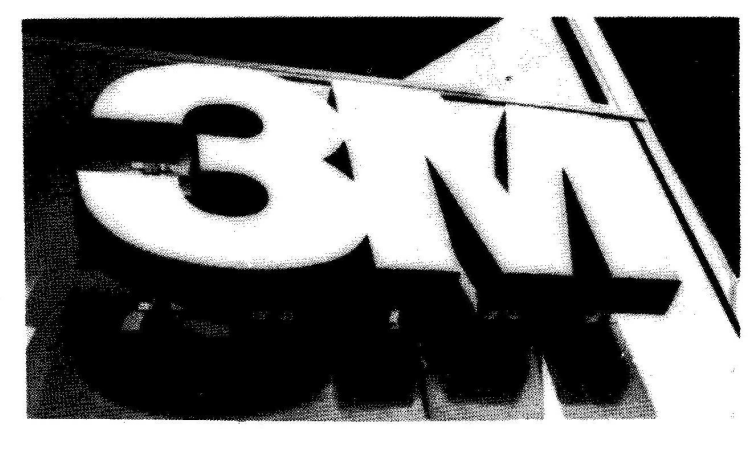

José Medina Rivaud, Arquitecto

$131-141$

\section{sinopsis}

Este edificio se ha construido en las inmediaciones de la autopista de Barajas y reúne todas las condiciones apetecidas en cuanto a ambientación, clima interior, iluminación natural y artificial, implantación en la naturaleza circundante, decoración y confort interior, etcétera.

Dispone de toda suerte de modernas instalaciones de todo tipo.

En especial se ha cuidado de todo lo referente al ahorro y conservación de energía.

La estructura y tratamiento exterior -fábrica de ladrillo a cara vista- son normales y en particular la primera consiste en pilares y placas nervadas de hormigón armado. 


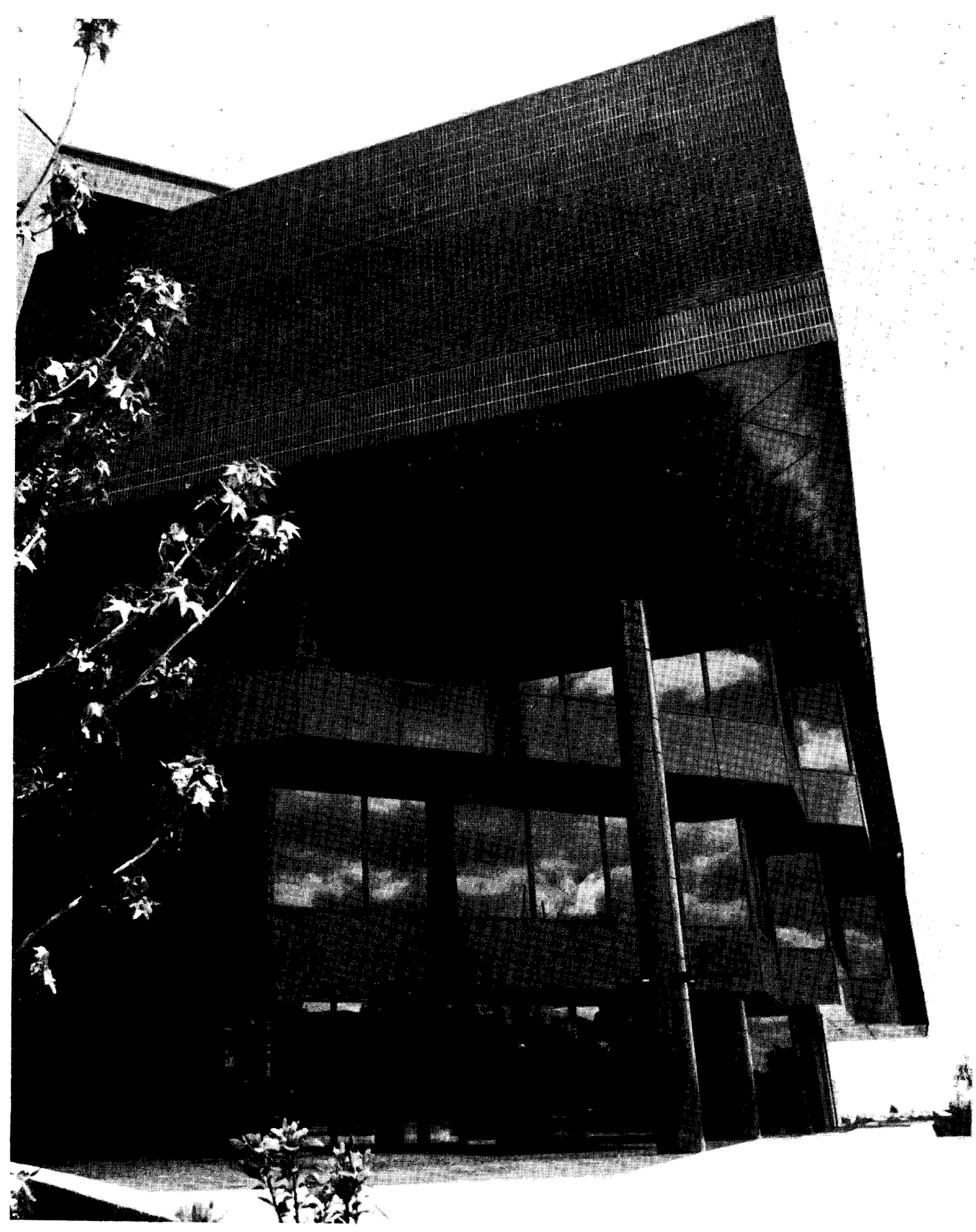

\section{GENERALIDADES}

\section{Implantación.}

El terreno, propiedad de la Compañía, se encuentra limitado al norte por la autopista de Barajas, al sur por la calle Josefa Valcárcel y sus costados oriente y poniente, por otros vecinos del sector, denominado Quinta de los Molinos.

La presencia de la autopista de Barajas y su futura ampliación, vías de servicio, paso sobre nivel y rampas de aproximación, imposibilitan, por ordenanza, un acceso directo al terreno desde ésta.

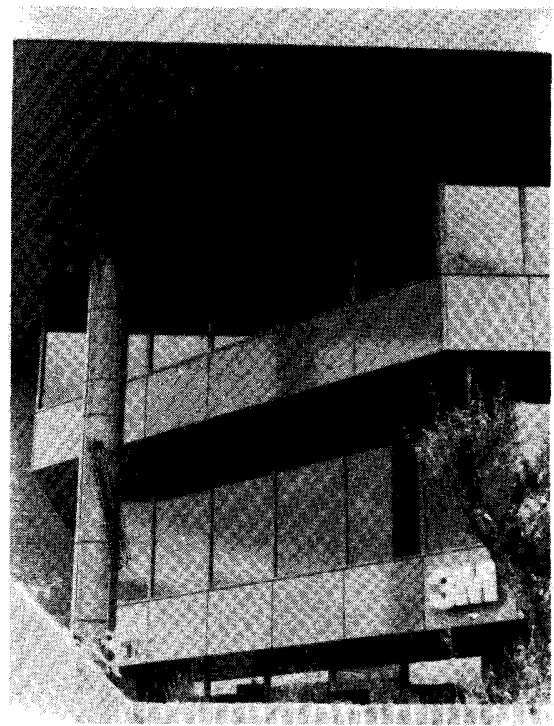




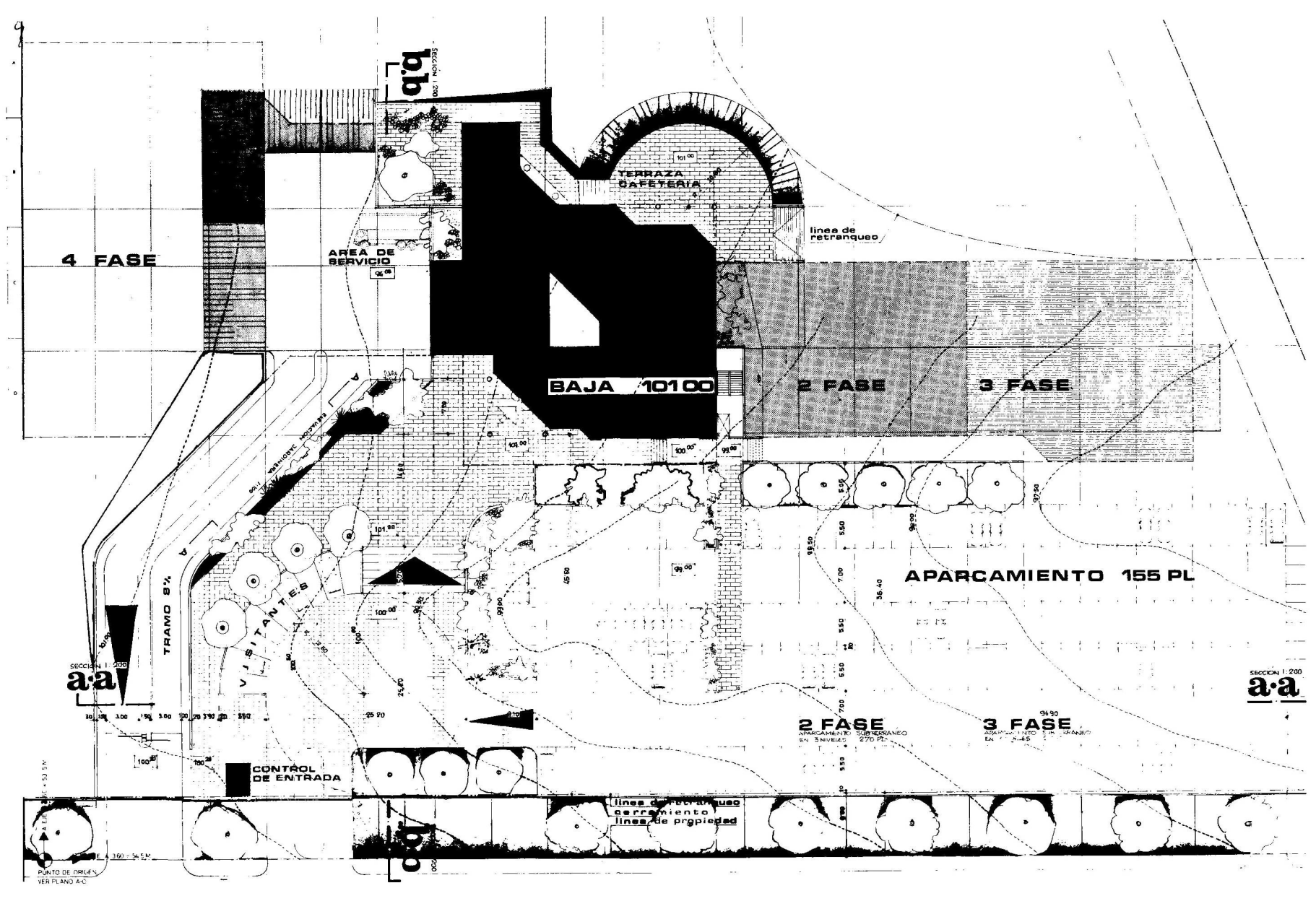

planta general

La entrada principal se encuentra por la calle de Josefa Valcárcel, actualmente con tráfico sólo desde dirección poniente, pero con acceso desde el oriente una vez se construya el paso sobre nivel correspondiente.

Se ha dividido el terreno en bandas paralelas de aparcamiento y de edificación, más una franja frente a la autopista que es de retranqueo obligatorio.

Estas bandas permiten el crecimiento del edificio en cuatro fases y el del aparcamiento, desde la actual área de superficie hasta una estructura de tres niveles.

El edificio actual fija la entrada principal al complejo definitivo. El crecimiento está establecido en dos fases hacia el oriente y una final hacia el poniente.

La estructura, así como los tratamientos exterior e interior son convencionales. 


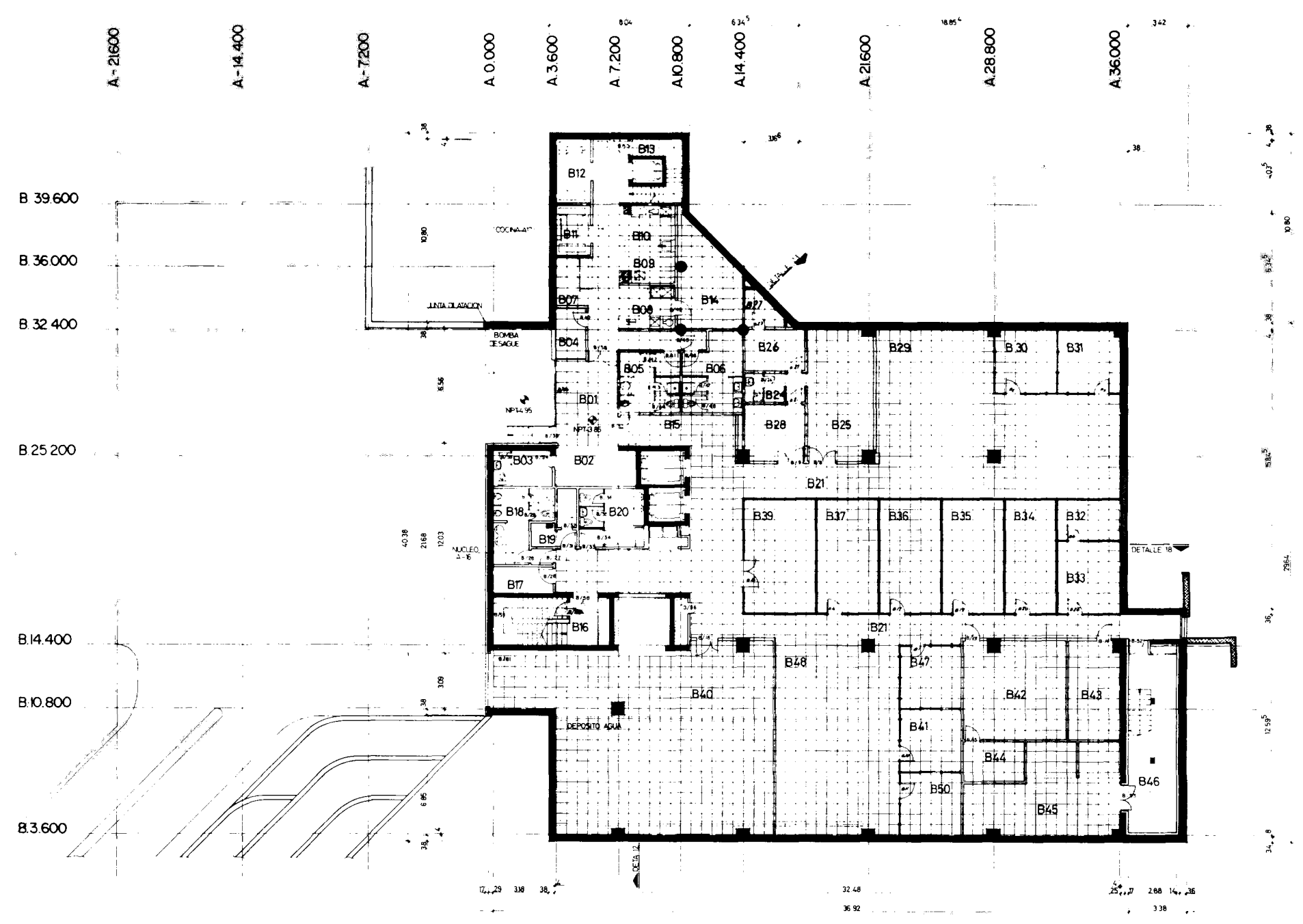

\section{CRITERIOS PRELIMINARES DE PROYECCION ARQUITECTONICA}

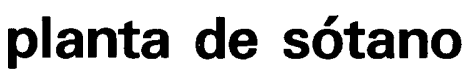

\section{Usuario.}

El criterio básico que regula el diseño es el de lograr las condiciones ambientales óptimas de temperatura, iluminación, vistas, decoración, etcétera..., para el empleo de la Compañía.

Al programar el edificio, se establecieron módulos para las distintas actividades que se desarrollan en el trabajo $y$, de acuerdo con ellas, se determinó la cuantía de espacio total.

Cambios de última hora y de organización desde el desarrollo del programa original, han causado algunos inconvenientes de ubicación para un sector del personal, que serán subsanados en cuanto se construya la próxima fase.

Se ha puesto especial énfasis en el diseño de las áreas comunes, aseos, fuentes de agua, ubicación especial de máquinas de bebidas, café y sobre todo el comedor-autoservicio. Los exteriores han sido pensados y proyectados para el disfrute del personal de la Compañía. 
El edificio disfruta de modernas y completas instalaciones de todo tipo.

\section{Ahorro de energía.}

El edificio es un organismo que consume grandes cantidades de energía. Debido a la situación mundial, por todos conocida, de consumo desenfrenado y por consiguiente el peligro de quedar desabastecidos a corto plazo, el pensamiento y la preocupación generalizada es encontrar medios de reducir el consumo energético. Un diseño coherente de edificio permite reducir los consumos espectacularmente. En el caso de nuestra Sede Social se han tomado en cuenta las siguientes premisas que afectan principalmente a su diseño:

\section{planta baja}

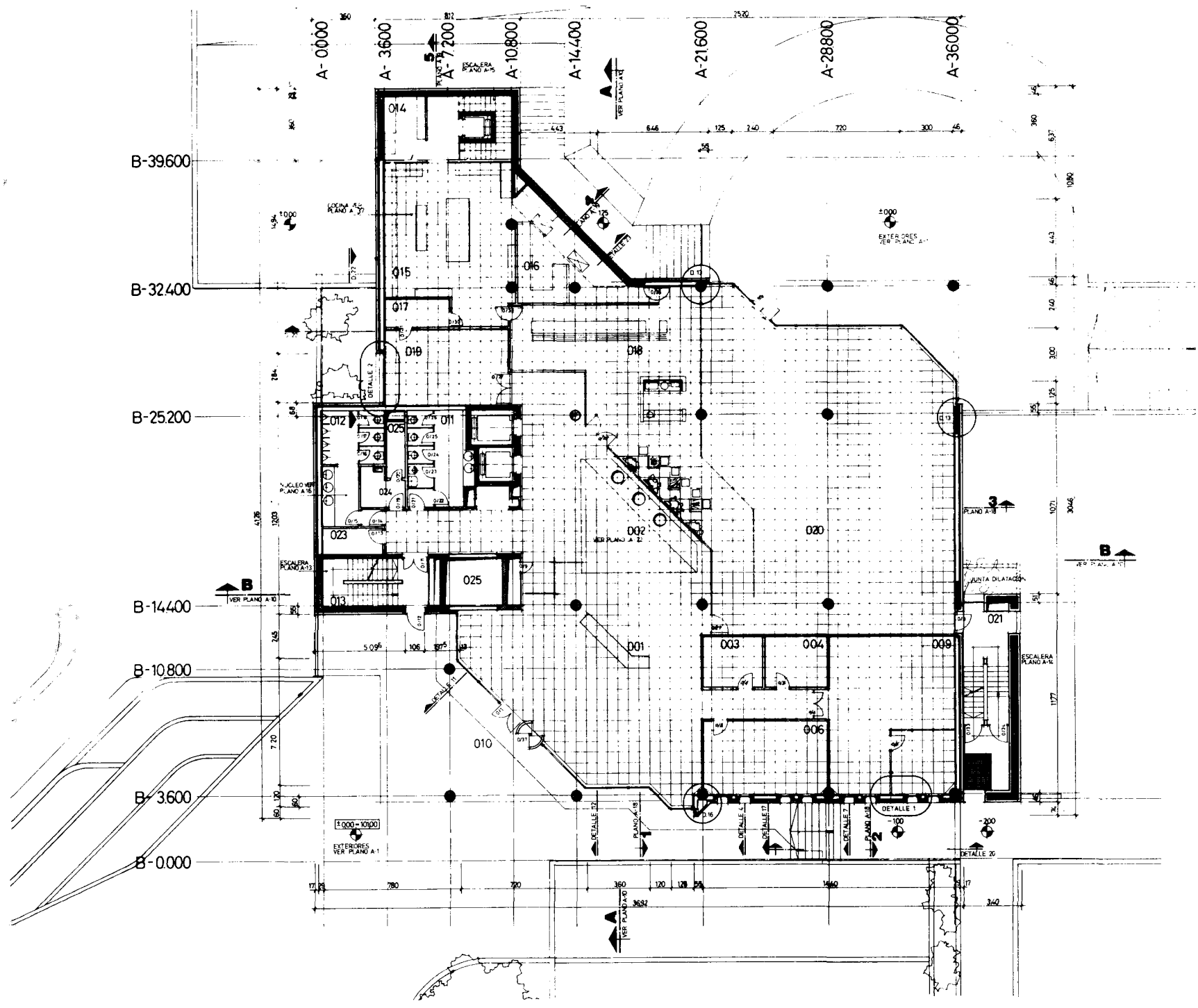




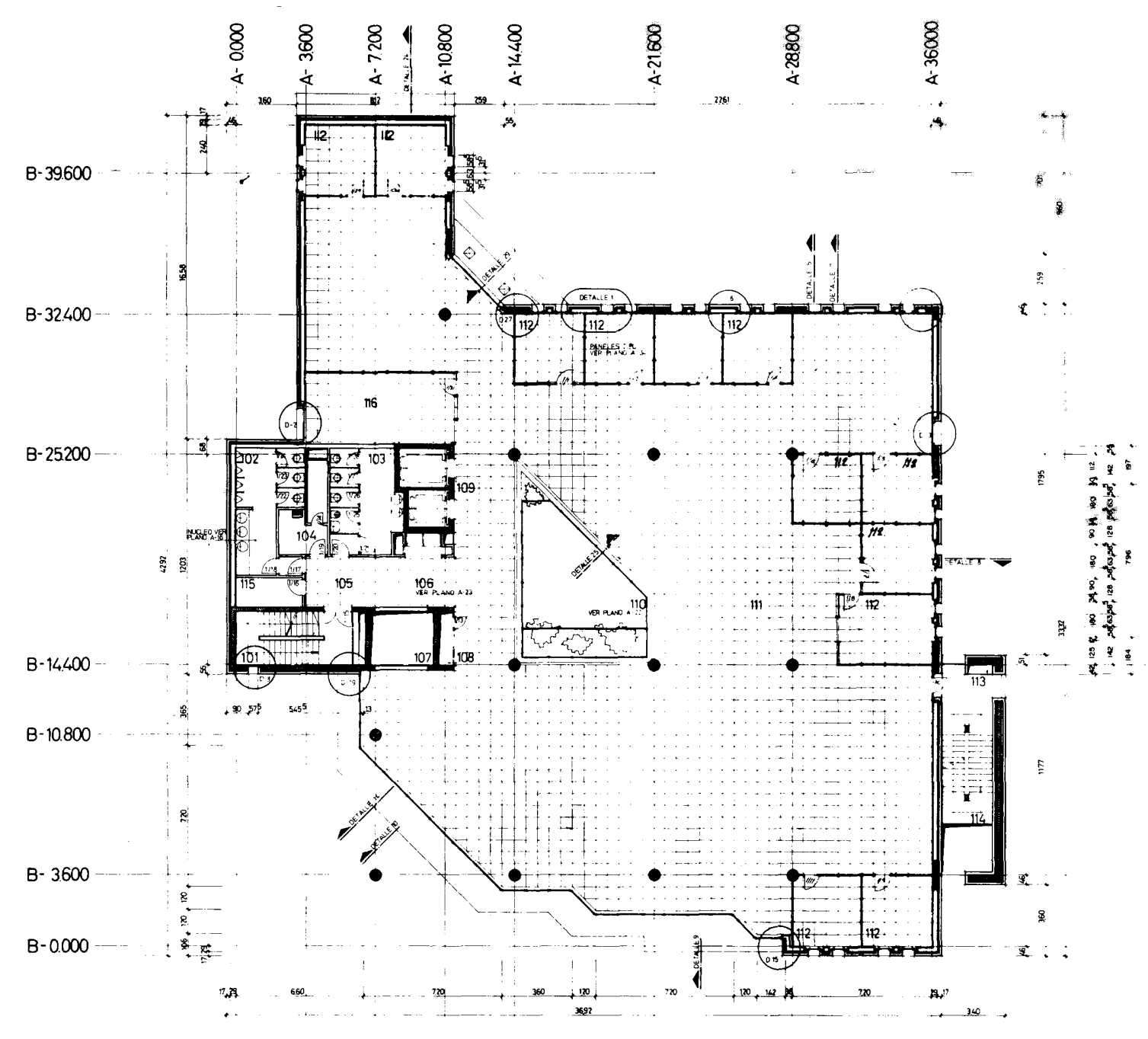

planta primera

a. Reducir al máximo las pérdidas de calor

Así nos aparece un volumen "cerrado» especialmente en su cara norte, muros gruesos aislantes con cámaras de aire, ventanas pequeñas con doble acristalamiento, etcétera.

b. Reducir al máximo las ganancias de calor

El edificio cuenta en sus zonas acristaladas con unas "viseras" que reducen la exposición directa y prolongada al sol, especialmente en su cara sur, lo que en el aspecto del edificio explica la presencia de los voladizos en la entrada principal. En las ventanas pequeñas se ha calculado que se encuentre el cristal en sombra la mayor parte del día.

Se agrega el hecho de haber sido utilizado en los cristales un material producido por la Compañía, el Scotchtint, que reduce por sí sólo, en un porcentanje elevado, las ganancias de calor por radiación solar. 
c. Lograr la mayor cantidad de luz natural con el mínimo de pérdidas de calor o ganancias de calor

Esto se logra fácilmente con un elemento usado desde hace mucho tiempo en la arquitectura: la claraboya. Se explica así que la misma superficie de ventanas, en un plano horizontal. arroja nueve veces más luz que una ubicación en un plano vertical y que, para los efectos de pérdidas y ganancias de calor, sólo se considera la superficie de la claraboya y no la cristalera del patio que encierra.

Debemos agregar en este apartado que el patio central cumple con una segunda función, la de convertirlo en un conducto de retorno de aire acondicionado. Esto lo transforma en un elemento de ahorro de energía, pues se ha logrado eliminar los conductos de retorno y la posible maquinaria (y energía) para mover el aire.

\section{planta tercera}

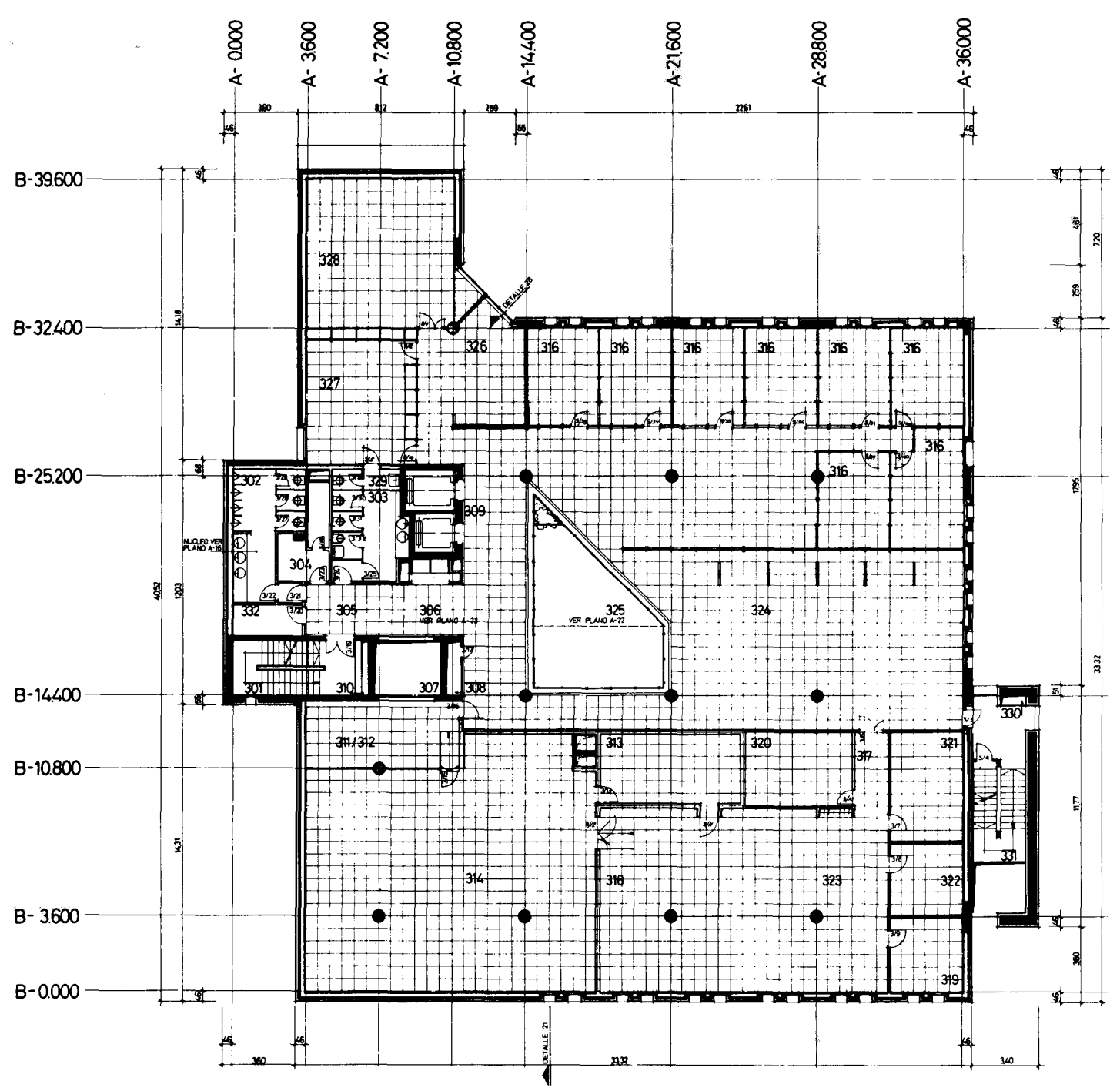




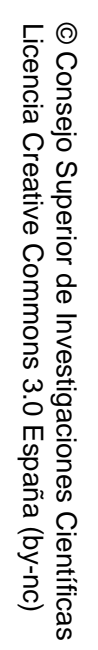

planta de ático

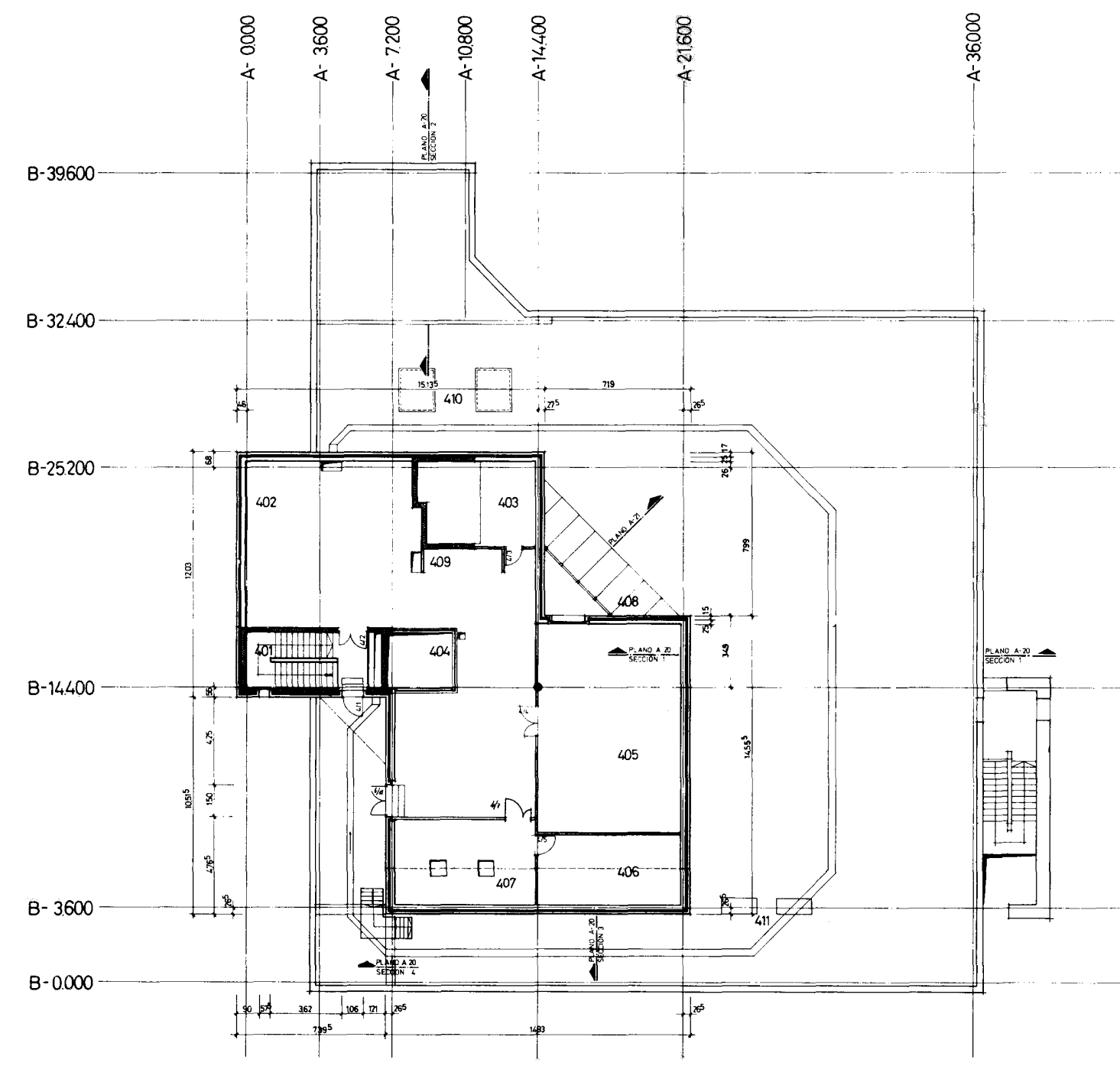

secciones
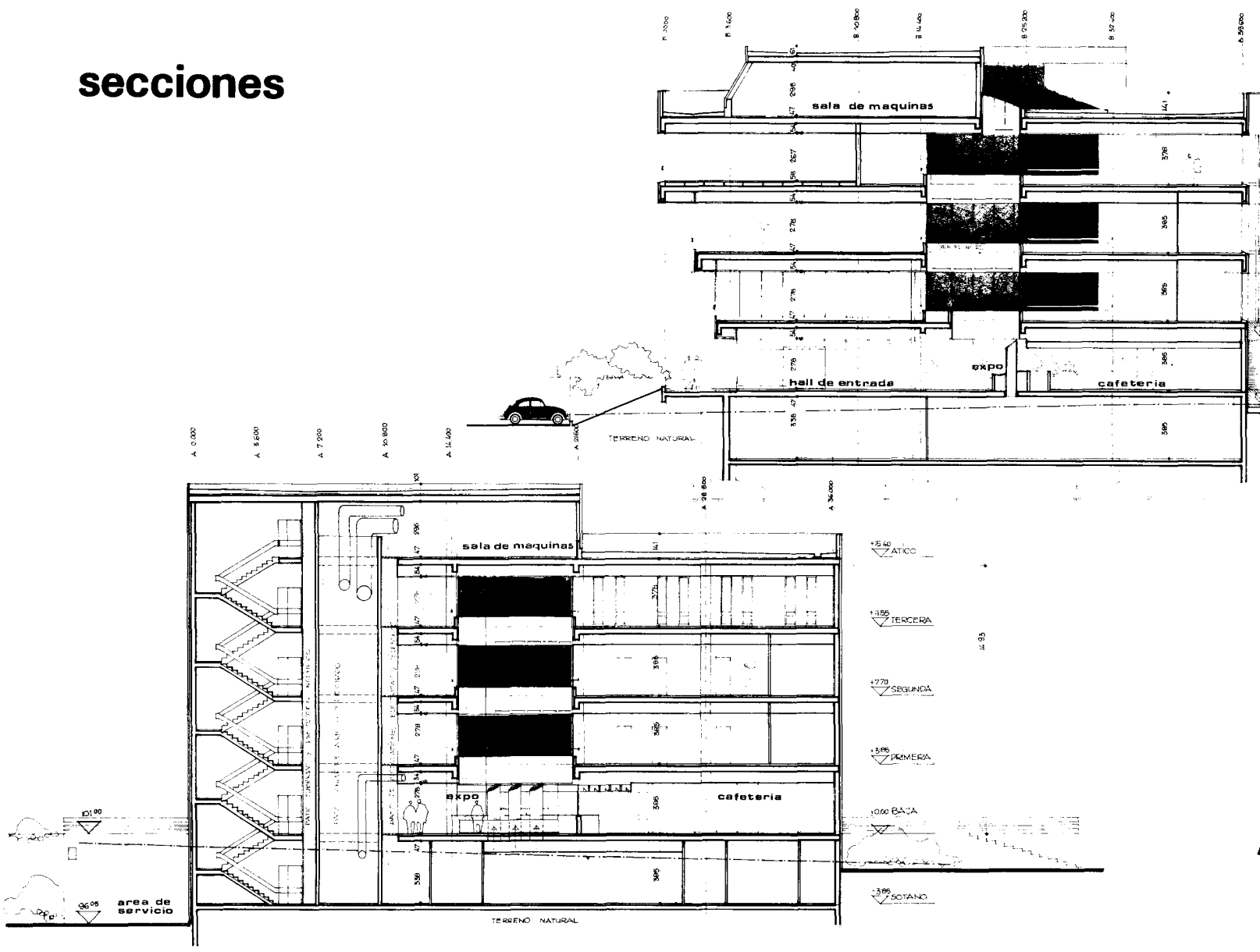

B-B 

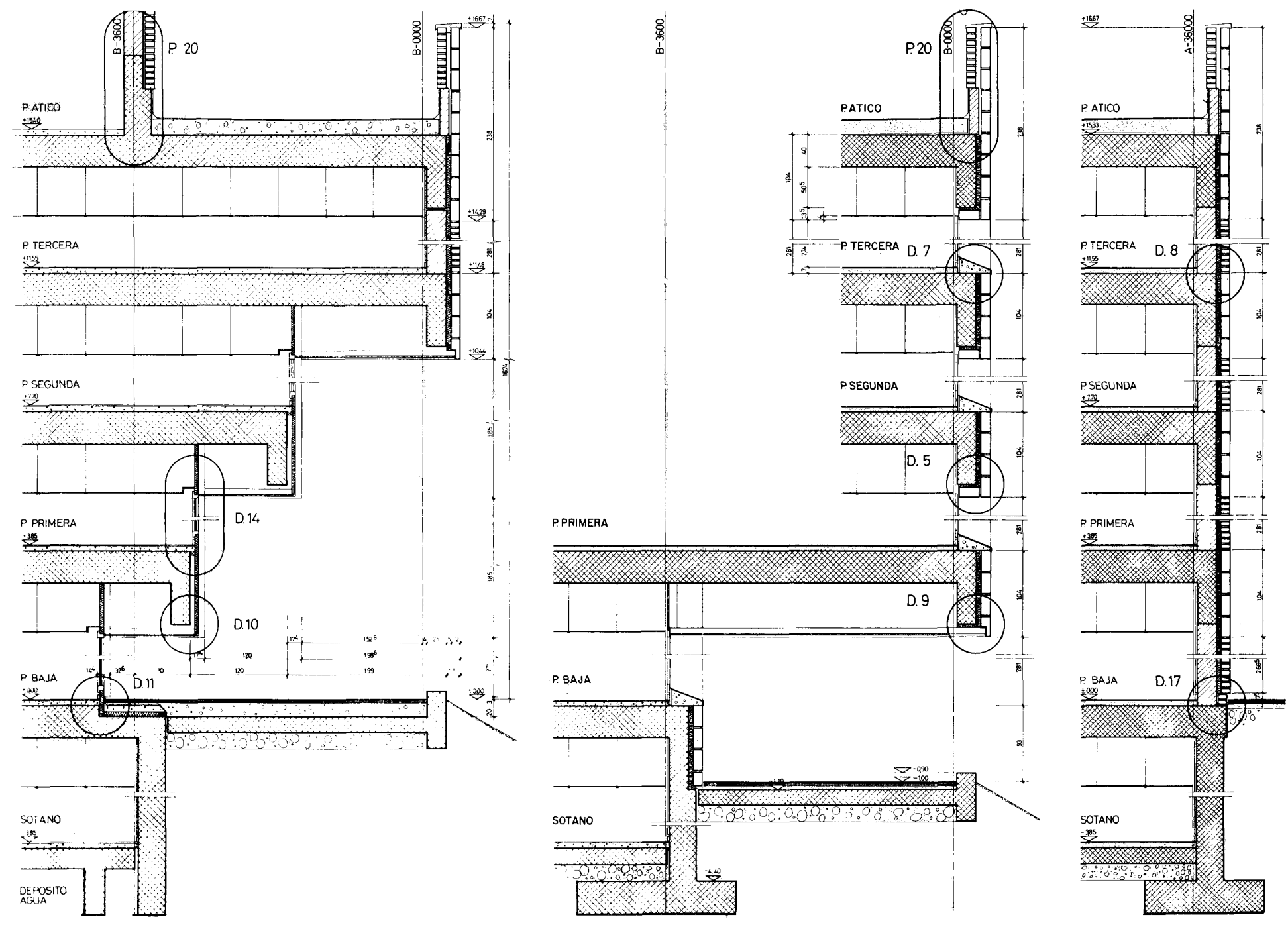

\section{detalles de cerramiento}

d. Lograr maximizar y recuperar la energía invertida en los sistemas mecánicos

Un sistema de refrigeración involucra, por su proceso, la compresión de un gas, que es enfriado debido a que pierde calor. Este calor, en los sistemas convencionales, es disipado y se pierde. El sistema de aire acondicionado con que cuenta el edificio aprovecha el calor al calentar agua, que es depositada en tanques para su posterior uso en calefacción o agua sanitaria. El principio se llama normalmente «bomba de calon».

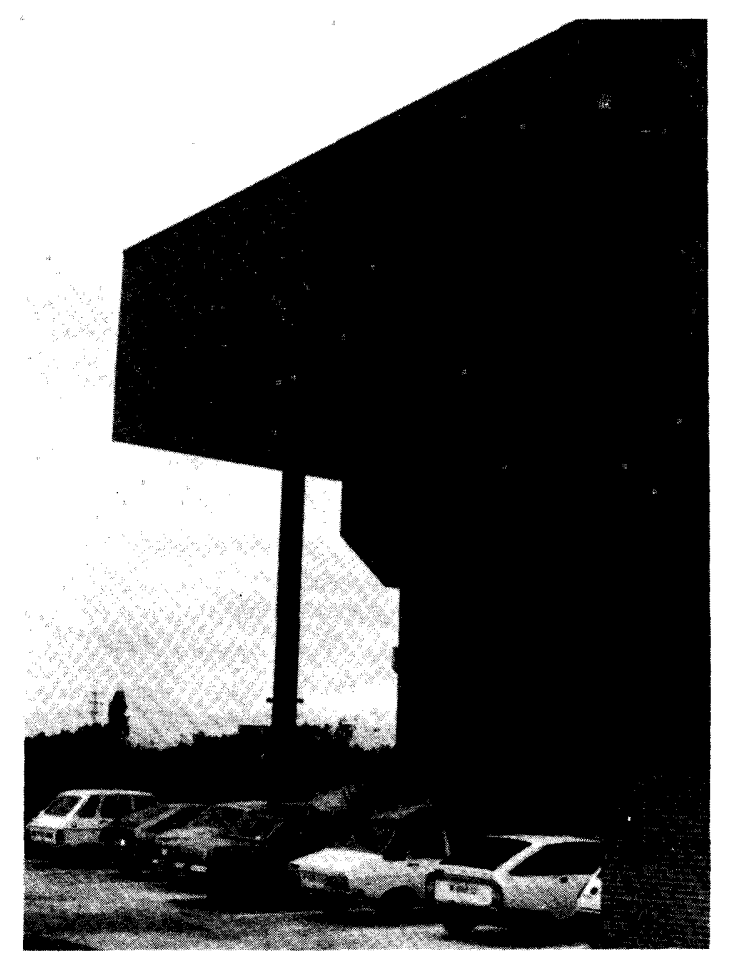




\section{detalles de cerramiento}
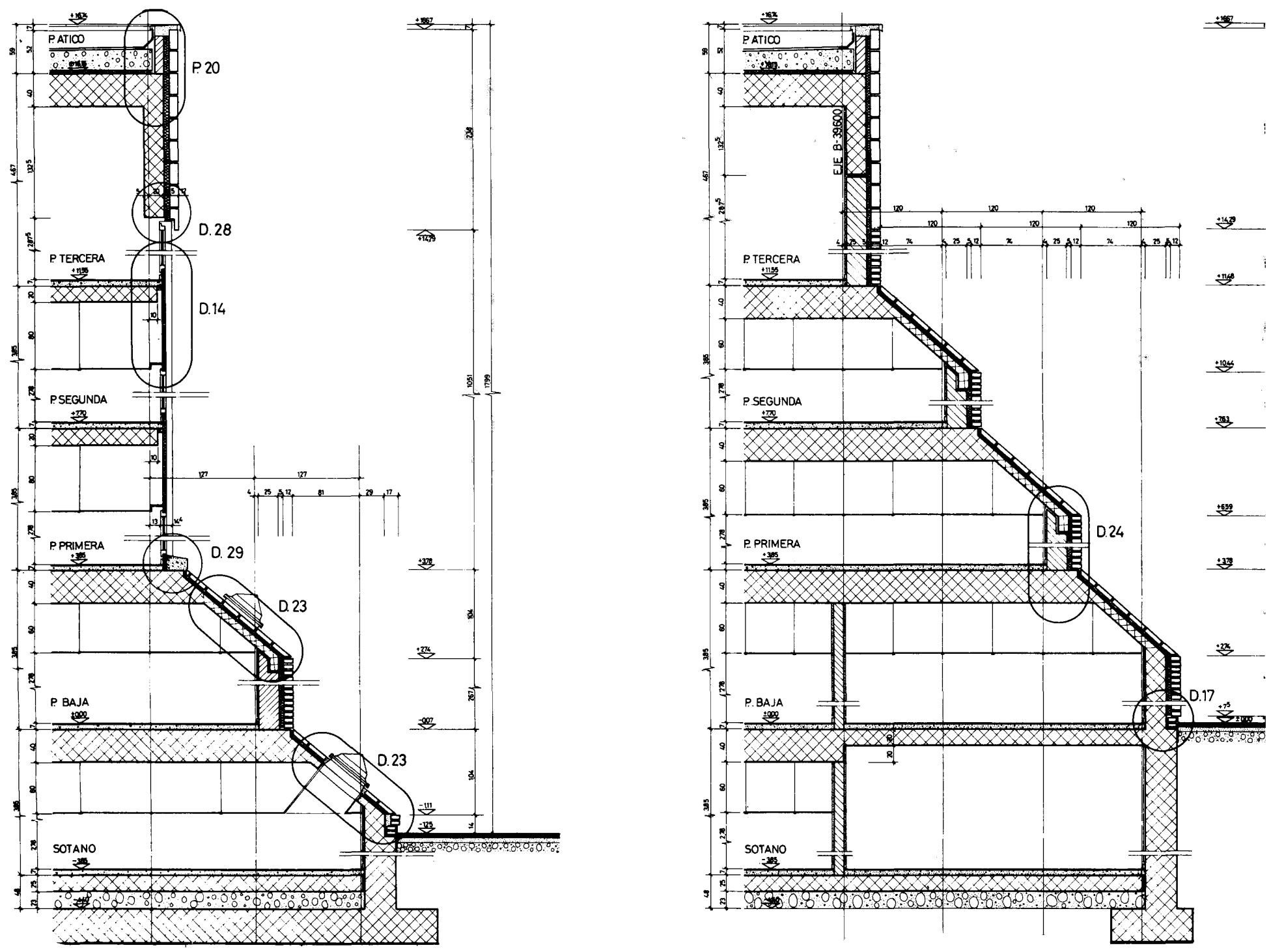

Los sistemas de ventilación expulsan aire viciado, por lo general caliente (como aseos, salas de reuniones, etcétera....). El edificio está dotado con un recuperador de este calor, que es de nuevo introducido al sistema energético del edificio.

A pesar de que el calor generado por un tubo fluorescente no es muy considerable, la mala ventilación del tubo incide en su vida real y en la cantidad de luz que emite. En el edificio, la ventilación de retorno se realiza a través de las pantallas de iluminación con lo que se logra mantener baja la temperatura del fluorescente y lograr por consiguiente las ventajas citadas con anterioridad.

\section{e. Energía solar}

Es notoria la existencia de un plano inclinado en la fachada sur del edificio. Este plano contendrá en un futuro no muy lejano una serie de baterías solares que proporcionarán agua caliente para uso doméstico y de calefacción. En estos momentos no se consideró viable financieramente su instalación, pero gracias a los avances espectaculares en este campo, se espera instalarlo pronto. 


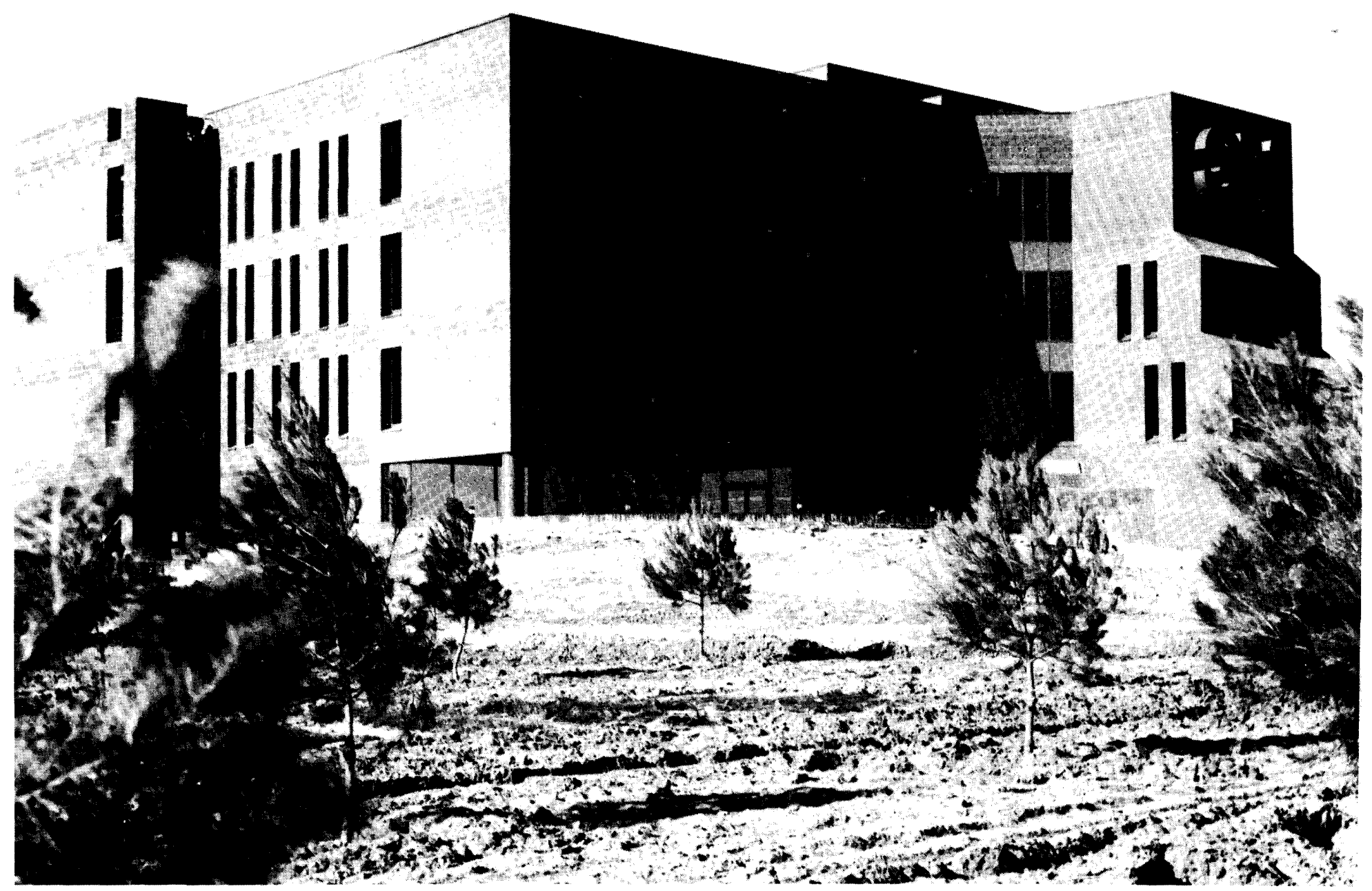

\section{Limitaciones de tipo legal}

Todo edificio debe respetar las ordenanzas de uso y condiciones volumétricas de la zona en que está enclavado. Las ordenanzas específicas de este sector limitan, por el momento, la altura de las edificaciones en $15 \mathrm{~m}$, o sea, una altura máxima de cuatro plantas para edificios de oficinas.

\section{Conclusiones}

Los párrafos precedentes dan una idea aproximada de los criterios preliminares considerados para la proyección de un edificio, sin constituir por sí mismos forma definitiva, ya que ésta será el resultado de la combinación e interpretación de dichas consideraciones por parte del proyectista.

\section{résumé}

\section{EDIFICE 3M À MADRID - ESPAGNE José Medina, architecte}

Cet édifice, bâti à proximité de l'autoroute de Barajas, remplit toutes les conditions voulues concernant l'ambiance, l'éclairage naturel et artificiel, la décoration et le confort intérieur, etc.

Il dispose de toute sorte d'installations modernes.

Une attention spéciale a été attachée à tout ce qui concerne l'économie et la conservation d'énergie.

La structure et le traitement extérieur - maconnerie de briques apparente- sont normaux. En particulier, la première consiste en des piliers et des dalles nervurées en béton armé.

\section{summary}

3M BUILDING IN MADRID - SPAIN José Medina, architect

This building was erected near the Barajas motorway and contains all desirable amenities to create a pleasant atmosphere, such as interior air handling facilities, natural and artificial lighting, decoration and comfortable interior designing and no effort was spared to blend the building into the surrounding natural environment.

All modern facilities are provided in the building and special care was placed in energy conservation

The structure in reinforced concrete ribbed slabs and columns and the external treatment in exposed brickwork is conventional but resolved with good taste.

\section{zusammenfassung}

3M-GEBÄUDE IN MADRID-SPANIEN José Medina, architekt

Dieses Gebäude wurde in der Nähe der Autobahn von Barajas erstellt und genügt allen Ansprüchen hinsichtlich Innenausstattung, Klimatisierung, natürlicher und künstlicher Beleuchtung, Einfügung in die natürliche Umwelt, Dekoration und Innenkomfort, usw.

Es verfügt über modeme Anlagen aller Art.

Es wurde besonderen Wert auf die Lösung aller Fragen der Energieeinsparung und -erhaltung gelegt.

Die Struktur und Ausführung des Aussenausbaus - Sichtziegelstein-Mauerwerk - sind normal, wobei im besonderen erstere aus Stützen und Rippenplatten aus Eisenbeton besteht. 